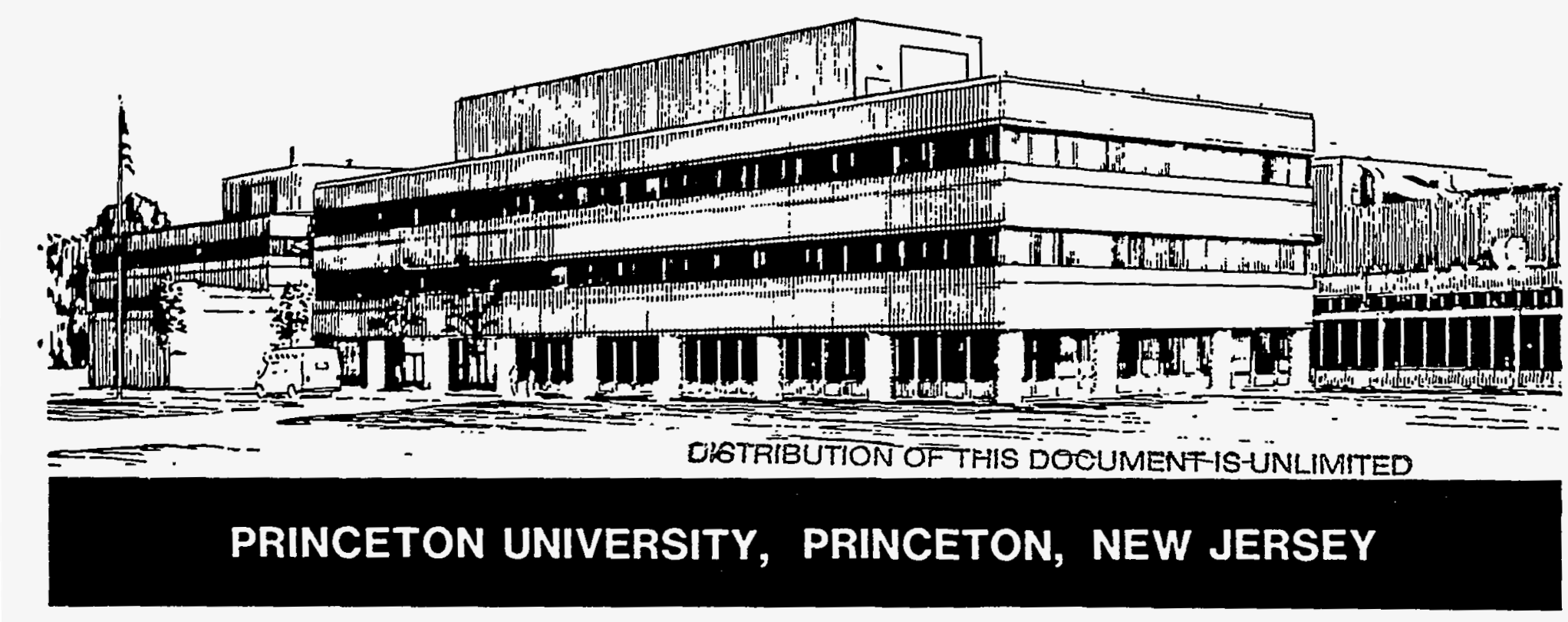




\section{NOTICE}

This report was prepared as an account of work sponsored by an agency of the United States Government. Neither the United States Government nor any agency thereof, nor any of their employees, makes any warranty, express or implied, or assumes any legal liability or responsibility for the accuracy, completeness, or usefulness of any information, apparatus, product, or process disclosed, or represents that its use would not infringe privately owned rights. Reference herein to any specific commercial produce, process, or service by trade name, trademark, manufacturer, or otherwise, does not necessarily constitute or imply its endorsement, recommendation, or favoring by the United States Government or any agency thereof. The views and opinions of authors expressed herein do not necessarily state or reflect those of the United States Government or any agency thereof.

\section{NOTICE}

This report has been reproduced from the best available copy.

Available in paper copy and microfiche.

Number of pages in this report: 25

DOE and DOE contractors can obtain copies of this report from:

Office of Scientific and Technical Information

P.O. Box 62

Oak Ridge, TN 37831 ;

(615) $576-8401$.

This report is publicly available from the:

National Technical Information Service

Department of Commerce

5285 Port Royal Road

Springfield, Virginia 22161

(703) $487-4650$ 


\section{DISCLAIMER}

Portions of this document may be illegible in electronic image products. Images are produced from the best available original document. 


\title{
ENERGETIC/ALPHA PARTICLE EFFECTS. ON MHD MODES AND TRANSPORT
}

C. Z Cheng, R. Budny, L. Chen1), M. Chu2), D. S. Darrow, E. D. Fredrickson, G. Y. Fu, T. S. Hahm, C. T. Hsu3), E. Mazzucato, H. E. Mynick, R. Nazikian, W. Park, N. Pomphrey, D. J. Sigmar 3), Y. Wu, R. B. White, S. J. Zweben

Princeton Plasma Physics Laboratory, Princeton University, P. O. Box 451, Princeton, NJ 08543

1) Department of Physics, University of California, Irvine, CA 92093

2) General Atomics, San Diego, CA 92186

3)Plasma Fusion Center, Massachusetts Institute of Technology, Cambridge, MA 02139

\begin{abstract}
A nonvariational kinetic-MHD stability code (NOVA-K) has been employed to study TAE stability in TFTR D-T and DIII-D experiments and to achieve understanding of TAE instability drive and damping mechanism. Reasonably good agreement between theory and experiment has been obtained. In these experiments the dominant damping mechanism is due to both the thermal ion Landau damping and/or the beam ion Landau damping. Based on ITER EDA parameters, the TAE modes are expected to be unstable in normal ITER operations. Energetic particle transport has been studied using a test particle code (ORBIT). Energetic particle loss scales linearly with the TAE mode amplitude and can be large for TFTR and DIII-D for $\delta \mathrm{B}_{\mathrm{r}} / \mathrm{B}>10^{-4}$ due to large banana orbit . From quasi-linear (ORBIT) and nonlinear kinetic-MHD (MH3D-K) simulations the saturation of TAE modes is due to nonlinear wave particle trapping and energetic particle profile modification in both radial and energy space. Finally, a convective bucket transport mechanism by MHD waves with time-dependent frequency is presented. Based on the energy-selective characteristics of the bucket transport mechanism, undesirable particles such as helium ash can be removed from the plasma core efficiently.
\end{abstract}
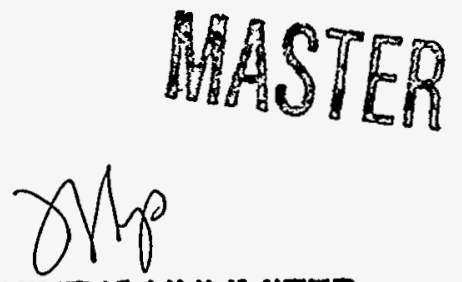

CSTRIBUTION OF THIS DOCUMENT IS UNLIMITED 
In a fusion reactor any unanticipated loss of energetic/alpha particle power could result in reduction of plasma beta, serious wall damage, impurity influx, major operational control problems, or even a failure to sustain ignition. NBI and ICRF experiments in large tokamaks have shown that collective MHD modes such as the fishbone and TAE modes [1,2] can be strongly unstable and cause the loss of up to half of the fast beam ions [3,4]. Recent TFTR DT experiments on TAE mode stability and theoretical NOVA-K code calculations have greatly increased our understanding of the alpha particle effect on TAE stability. On the other hand, deliberate excitation of MHD modes such as TAE modes might be employed to remove undesirable particles such as Helium ash.

The low frequency fishbone modes are the $n=1$ internal kink type modes destabilized by the $\omega=\omega_{d}$ resonance with energetic trapped particles, where $\omega_{d}$ is the energetic trapped particle bounced-averaged magnetic drift frequency. Since $\omega_{d}$ is a function of particle velocity, pitch angle, aspect ratio, plasma beta, and plasma shaping, the magnetic drift reversal domain in the pitch angle and minor radius space can be significantly enlarged. Alpha particles have a uniform velocity pitch angle distribution, and their averaged magnetic drift frequency can be significantly reduced so that the theoretical $\beta_{\alpha}$ threshold for the fishbone instability becomes much lower than previously thought [5]. This conclusion is also supported by the previous NOVA-K code calculations of the alpha fishbones for TFTR and ITER plasmas [6].

In this paper we concentrate on the energetic/alpha particle effects on the TAE modes. The energetic/alpha particle effects on the TAE stability for TFTR DT experiments, DIII-D experiments and ITER EDA parameters are analyzed with the NOVA-K code $[7,8]$ and given in Section 1 . The energetic/alpha particle transport due to TAE modes by test particle analysis (ORBIT code [9]) as well as quasi-linear [10] and nonlinear kinetic-MHD (MH3D-K code [11]) simulations are presented in Section 2. In Section 3 a new convective "bucket" transport mechanism by employing magnetic perturbations with chirped (time-dependent) frequency, and its application for Helium ash removal are presented [12,13]. A summary is given in Section 4.

\section{Energetic/Alpha Particle Effects on TAE Modes}

The TAE modes $[1,2]$ have been shown to exist with discrete frequencies located inside the shear Alfvén continuum gaps created due to toroidal coupling of different poloidal harmonics. The analytical expression for continuum gap structure has previously been obtained, and it depends on the plasmà beta, shaping, and aspect ratio $[14,15]$. The frequency of the TAE mode in the lowest 
continuum gap is roughly given by $\omega \approx \mathrm{V}_{\mathrm{A}} / 2 \mathrm{qR}$ for all toroidal mode numbers. The existence of TAE modes depends on the plasma density and q profiles, plasma $\beta$, plasma shaping, and wall $[14,15]$.

TAE modes can be driven unstable by energetic/alpha particles through wave-particle resonance by tapping the free energy associated with the energetic/alpha particle pressure gradient [16-18]. To destabilize the TAE mode, the instability drive associated with the energetic/alpha particle pressure gradient must overcome velocity space and collisional damping effects due to all particle species. The NOVA-K code contains linear physics such as ion Landau damping, electron Landau damping, trapped electron collisional damping, damping or drive from neutral beam ion and ICRF fast minority ions, alpha particle drive. The effect of finite orbit excursion from the flux surface is included. If the TAE mode suffers continuum damping, this effect can be computed with the resistive NOVA-R code [19] and then added to the NOVA-K calculation. The effects due to finite Larmor radius (FLR) and the parallel electric field are neglected in the NOVA-K code.

One way to reduce or even stabilize the TAE instability is to control the $v_{A}(r)$ and $q(r)$ profiles so that the radial gap structure does not line up across the minor radius, and the TAE mode will experience continuum damping. Another way is to increase plasma $\beta$. As the plasma $\beta$ exceeds the ballooning mode $\beta$ limit or the magnetic shear decreases to zero, the TAE frequency will move downward into the lower continuum and suffer continuum and radiation damping. Continuum damping of the TAE modes has been studied numerically with the NOVA-R code, and the continuum damping rate is typically less than $1 \%$ of the real frequency [15].

\subsection{TAE Instabilities in TFTR D-T Experiments}

The stability of TAE modes for the first phase of TFTR D-T experiments [20,21] has been analyzed with the NOVA-K code. The plasma profiles are provided by the TRANSP analysis code which models the D-T supershot plasmas. In most of the high NBI-powered DT discharges alphadriven TAE modes have not been observed. However, in one NBI DT discharges there is an enhancement in the Alfvén frequency spectrum peak over similar D-D discharges, which suggests that TAE modes are excited. Theoretical analysis of these DT experiments using the NOVA-K code agrees well with the TAE experimental results and provides physical insights of the TAE driving and damping mechanism in each experiment.

The NOVA-K stability calculations of TAE modes with $n=1-6$ for most high NBIpowered DT supershot plasmas indicate that the TAE modes will be at most marginally stable in 
most of these D-T experiments, consistent with the D-T experiments. Consider a TFTR DT discharge with a 50\%-50\% mixture of Deuterium and Tritium and $6 \mathrm{MW}$ fusion power (shot \# 73268 at $3.4 \mathrm{sec})$. The plasma parameters are the volume averaged plasma beta $\langle\beta\rangle=0.89 \%$, $\beta(0) \approx 4.6 \%$, the volume averaged alpha particle beta $\left\langle\beta_{\alpha}\right\rangle \approx 0.03 \%, \beta_{\alpha}(0) \approx 0.18 \%, n_{e}(0) \approx 7.6$ $\times 10^{13} \mathrm{~cm}^{-3}, \mathrm{~T}_{\mathrm{i}}(0) \approx 28 \mathrm{keV}, \mathrm{T}_{\mathrm{e}}(0) \approx 10.5 \mathrm{keV}, \mathrm{q}(0) \approx 0.84, \mathrm{q}(\mathrm{a}) \approx 5.1$, and $\mathrm{v}_{\alpha} / \mathrm{v}_{\mathrm{A}}(0) \approx 1.54$. The fixed parameters of TFTR D-T experiments are a circular cross section with the major radius $R$ $=252 \mathrm{~cm}$, the minor radius $\mathrm{a}=87 \mathrm{~cm}$, the toroidal field $\mathrm{B}=5 \mathrm{~T}$, and the plasma current $\mathrm{I}_{\mathrm{p}}=2$ MA. For this discharge there is only one TAE mode for each toroidal mode number in the range $n$ $=1-6$, and no TAE mode for $\mathrm{n}>6$. The TAE modes have global radial structure covering from $1 / 2$ minor radius to the plasma edge. The TAE modes that correspond to continuum gaps near the plasma center do not exist due to large pressure gradient in these supershot plasmas. Figure 1 shows the critical central alpha particle beta $\beta_{\alpha}(0)$ for TAE instability versus the toroidal mode number. The experimental $\beta_{\alpha}(0)$ value is about $1 / 3$ of the $\beta_{\alpha}(0)$ threshold for the $n=5$ mode. For the medium-n TAE modes the dominant damping mechanisms are found to be the thermal and deuterium beam ion Landau damping. The tritium beam Landau damping is much smaller than the deuterium beam damping due to slower velocity. The electron Landau damping and trapped electron collisional damping are also smaller than the beam ion Landau damping.

In one NBI-powered DT discharges there is a clear enhancement in the Alfvén frequency spectrum peak over similar D-D discharges, which suggests that TAE modes are excited by alphas. NOVA-K calculation shows that in these discharges the TAE modes are found to be localized near the plasma core (near the $\mathrm{q}=1$ surface). Since the existence of the TAE modes and their mode structure depend sensitively on $\mathrm{p}^{\prime}(\mathrm{r})$, such core localized TAE modes can exist if the plasma pressure profile is slightly broader. Such core localized TAE modes can be unstable because they are localized in the region where alpha pressure is highly peaked and the destabilizing contribution is largest. These core localized TAE modes have very small amplitude near the plasma edge and their signals detected by the Mirnov coils will be very weak. The alpha loss due to these core localized TAE modes is also expected to be small. Figure 2 shows the theoretical radial structure of the poloidal harmonics of radial displacement $\xi_{\psi}$ of the $n=5$ fixed boundary TAE mode for a TFTR D-T shot (\#76770 at $4.31 \mathrm{sec)}$ with 7.5 MW peak fusion power. The corresponding plasma parameters are the volume averaged plasma beta $\langle\beta\rangle=0.82 \%, \beta(0) \approx 3.1 \%$, the volume averaged alpha particle beta $\left\langle\beta_{\alpha}\right\rangle \approx 0.049 \%, \beta_{\alpha}(0)=0.24 \%, \mathrm{n}_{\mathrm{e}}(0) \approx 7.5 \times 10^{13} \mathrm{~cm}^{-3}, \mathrm{~T}_{\mathrm{i}}(0) \approx 19 \mathrm{keV}$, $\mathrm{T}_{\mathrm{e}}(0) \approx 11 \mathrm{keV}, \mathrm{q}(0) \approx 0.88, \mathrm{q}(\mathrm{a}) \approx 4.1$, and $\mathrm{v}_{\alpha} / \mathrm{v}_{\mathrm{A}}(0) \approx 1.55$. We note that the pressure and density profiles are relatively broader than in shot \#73268. The $n=5 \mathrm{TAE}$ mode frequency is given by $\left(\omega / \omega_{A}\right)^{2}=4.04$, where $\omega_{A}=V_{A}(0) / q(a) R$. The dominant damping mechanism is due to both the thermal ion Landau damping and the deuterium beam ion Landau damping. The $\mathrm{n}=5$ and 
$6 \mathrm{TAE}$ modes are unstable with the alpha drive about a factor of 2 higher than the total damping rate.

To excite TAE instability in future TFTR D-T experiments, one should try to reduce the thermal and beam ion Landau damping, and enhance the alpha drive. The beam ion Landau damping can be reduced with less beam power or lower injection energy. In one case study the beam damping can be reduced by a factor of 4 if the beam injection energy is reduced by $30 \%$. Since the thermal ion Landau damping rate decreases rapidly with thermal ion beta roughly according to $\beta_{\mathrm{i}}{ }^{-3 / 2} \exp \left(-1 / 9 \beta_{\mathrm{i}}\right)$, we can try to reduce the thermal ion beta by reducing either beam power (or core plasma $\beta$ ). The thermal ion beta can also be lowered by reducing ion temperature by either helium gas puffing or pellet injection. To amplify the alpha drive, $q(0)$ can be raised transiently by ramping the plasma current, pushing the Alfvén continuum gap into the region of maximum alpha pressure gradient. The discharge evolution can also be tailored so as to produce a "hollow shell" alpha energy distribution, which should increase the free energy to drive the TAE mode. Additional TAE instability drive such as ICRH tail ion drive can also enhance the possibility of TAE instability.

One experiment was performed in TFTR to rapidly reduce the ion temperature and thermal ion Landau damping of TAE modes in high NBI-powered D-T supershots by puffing He gas or by injecting D or Li pellets. With He puffs during NBI, the central ion temperature was successfully reduced from $25 \mathrm{keV}$ to $10 \mathrm{keV}$ in about $0.2 \mathrm{sec}$, while the alpha pressure was reduced about a factor of two. Increases in MHD activity near the Alfvén frequency were observed after these cooling perturbations, but similar increases were seen for both D-T and D-D plasmas, implying that this change was not due to the presence of alpha particles in D-T plasma. Analysis of these discharges by the NOVA-K code showed that the thermal ion Landau damping was significantly reduced by the He puff cooling perturbation for $n=1,2$ modes, but the Landau damping from $D$ beam ions was the dominant damping mechanism in the D-T discharges. The conclusion was that the alpha beta in the D-T discharges was not sufficiently high to excite alpha-driven TAE instability, in agreement with the experimental results.

\subsection{TAE Instabilities in DIII-D}

TAE modes have been excited by injected energetic neutral beam ions in DIII-D. A discharge (shot \# 71524) has been analyzed by the NOVA-K code to compare with the experimental observation. The plasma parameters of the discharge are given by $R=1.67 \mathrm{~m}, \mathrm{a}=$ 
$0.67 \mathrm{~m}$, the ellipticity $\kappa \approx 1.6$, the triangularity $\delta \approx 0.25$, the toroidal field $\mathrm{B}=0.8 \mathrm{~T}$, the plasma volume averaged beta $\langle\beta\rangle=3.9 \%$, the line averaged electron density $\left\langle n_{e}\right\rangle=3 \times 10^{13} \mathrm{~cm}^{-3}$, the central electron temperature $T_{e}(0)=1.9 \mathrm{keV}$, the central thermal deuterium ion temperature $T_{i}(0)=$ $2.3 \mathrm{keV}, \mathrm{q}(0) \approx 0.85$, and $\mathrm{q}(\mathrm{a}) \approx 4.95$. The deuterium beams are injected at $79 \mathrm{keV}$ of injection energy with $5 \mathrm{MW}$ of total beam power. As shown in Fig. 3(a) TAE modes with $n=1-5$ have been observed with signal being the strongest for $n=3$ and much weaker for $n=1$ or 5 [22]. TAE modes appear in bursts with repetition rate increasing with beam power and can effectively clamp the number of energetic ions in the plasma. The experimentally observed frequencies and mode structures are in reasonable agreement with theoretical solutions of TAE modes obtained from NOVA-K code. The dominant damping mechanism is the thermal ion Landau damping which decreases with the toroidal mode number. The beam drive is relatively independent of $n$ so that the net growth rates of TAE modes increases with $n$. The TAE growth rate versus $n$ computed from the NOVA-K code is shown in Fig. 3(b). The $n=1$ TAE is near marginal stability, consistent with experimental observation. The $n=2$ TAE mode has been computed to be marginally stable, in contradiction to experimental observation. Also, higher $n(n>3)$ TAE modes have been found to have higher growth rate than experimental observation. Possibilities for the disagreement may be due to poor knowledge of plasma profiles, the neglect of radiation damping effect in the NOVA$\mathrm{K}$ code, or nonlinear effect on TAE saturation. In particular, radiation damping associated with thermal ion FLR effects can be significant for higher $\mathrm{n}$ modes due to relatively weak toroidal field in the DIII-D experiments. These will be investigated in the future.

\subsection{TAE Instabilities in ITER}

Stability of TAE modes in ITER has also been studied based on the ITER EDA design parameters. Based on PRETOR plasma profiles (very flat pressure and q profiles for $r / a<0.7$ ), NOVA-K calculation finds that TAE modes are stable. However, the PRETOR profiles are probably unrealistic and we have employed relatively more realistic plasma profiles for the NOVA-

$\mathrm{K} T \mathrm{TAE}$ stability calculation. We find that TAE modes can be more easily destabilized than in the TFTR D-T experiments. One reason is because ITER has higher current (and lower $\mathrm{q}(\mathrm{a}) \approx 3.5$ ) and its plasma beta is below the Troyon limit so that TAE modes can exist with more global radial structure. Another reason is that the expected $\left\langle\beta_{\alpha}\right\rangle$ is about one order of magnitude larger than in TFTR D-T experiments.

To study the TAE instabilities for ITER experiments we will consider a series of equilibria with varying plasma beta. The fixed parameters of the ITER equilibrium are taken to be the major 
radius $R=8.1 \mathrm{~m}$, the minor radius $\mathrm{a}=3 \mathrm{~m}$, the ellipticity $K=1.7$, the triangularity $\delta=0.3$, the toroidal field $B=5.7 \mathrm{~T}$. The pressure profile is chosen as $P=P(0)(1-\psi)^{2}$, where $\psi$ is the normalized poloidal flux. The q-profile is chosen with $\mathrm{q}(0)=1.01, \mathrm{q}(1)=3.78, \mathrm{q}^{\prime}(0)=0.5$, $\mathrm{q}^{\prime}(1)=13$. The plasma is assumed to consist of thermal electron, thermal D-T ions and alpha particles. The electron density profile is given by $n_{e}=n_{e}(0)\left(1-0.8 \psi^{2}\right)$. The thermal ions are assumed to consist of an equal mixture of $D$ and $T$ with equal temperature. We assume $n_{i}=n_{e}$ and $\mathrm{T}_{\mathrm{i}}=\mathrm{T}_{\mathrm{e}}$. For $\mathrm{n}_{\mathrm{e}}(0)=10^{14} \mathrm{~cm}^{-3}$ and $\mathrm{T}_{\mathrm{e}}(0)=28 \mathrm{keV},\langle\beta>=1.5 \%$. The alpha pressure profile is chosen to be proportional to $\mathrm{P}(\mathrm{r})^{3.5}$. Based on these ITER equilibria the stability of TAE modes has been analyzed for $n \leq 20$. For an ITER equilibrium the TAE growth rate increases with $n$, and thus the critical $\left\langle\beta_{\alpha}\right\rangle$ decreases with $\mathrm{n}$. The ion Landau damping is the dominant damping mechanism and increases rapidly with $\left\langle\beta_{\mathrm{i}}\right\rangle$. However, the alpha drive also increases with $\left\langle\beta_{\mathrm{i}}\right\rangle$. Figure 4 shows the stability boundary in the $n_{e}(0)-T(0)$ POPCON diagram for $n=15$ TAE mode. The $\mathrm{n}=15$ TAE mode will be unstable for $n_{\mathrm{e}}(0)<10^{14} \mathrm{~cm}^{-3}$. Higher $\mathrm{n}(\mathrm{n}>15)$ TAE modes will have higher density threshold. Since ITER is expected to operate in the range $2 \times 10^{14} \mathrm{~cm}^{-3} \geq n_{\mathrm{e}}(0)$ $\geq 5 \times 10^{13} \mathrm{~cm}^{-3}$ and $30 \mathrm{keV} \geq \mathrm{T}(0) \geq 10 \mathrm{keV}$, TAE modes may be destabilized in ITER experiments.

We note that in actual ITER experiments there may be other high energy particle species such as ICRH minority tail ions and high energy beam ions, which can contribute additional TAE instability drive and lower the instability threshold. On the other hand, $q(r)$ and $n_{e}(r)$ profiles can be controlled to provide continuum damping and stabilize the TAE modes. Therefore, TAE stability in ITER needs to be investigated further with more realistic plasma profiles and more particle species.

\section{Energetic/Alpha Particle Transport due to TAE Modes}

Large energetic particle loss induced by TAE activity as high as $80 \%$ has been observed in tokamak experiments [3,4]. The anomalous energetic/alpha particle loss due to MHD modes such as TAE modes has been studied by (1) stochastic orbit theories and a Hamiltonian guiding center orbit code, ORBIT, and (2) quasi-linear and nonlinear kinetic-MHD (MH3D-K code) simulations.

\subsection{Transport due to TAE Modes}

TAE modes destabilized by energetic particles can lead to large loss of energetic particles as has been found both experimentally and theoretically in both TFTR and DIII-D. As previously 
pointed out $[9,15]$, there are two basic mechanisms that lead to loss of energetic particles when interacting with TAE modes: (1) near boundary transient loss and (2) stochastic diffusion loss across the prompt loss boundary in the phase space of particle energy, pitch angle, and toroidal angular momentum. These loss mechanisms have been verified by test particle simulation using the MIT-modified ORBIT code [9] for particle loss due to TAE modes obtained by the NOVA-K code in both TFTR DT and DIII-D equilibria.

Due to the distorted particle drift orbit by TAE modes, the near boundary loss will last for a few bounce times of particles trapped in the waves provided that there is no particle source. For particles trapped inside a well-defined resonant drift orbit island intersecting with the prompt loss boundary, their loss rate scales as $\left(\delta \mathrm{B}_{\mathrm{r}} / \mathrm{B}\right)^{1 / 2}$. If the particle loss is due to distorted orbit not close to the resonant drift orbit island, the transient loss rate scales as $\left(\delta \mathrm{B}_{\mathrm{r}} / \mathrm{B}\right)$. The stochastic diffusion loss will last longer. The diffusion loss mechanism arises from the overlap of particle drift orbit islands in the Poincare surface of section. The stochastic threshold for a single TAE mode is $\left(\delta \mathrm{B}_{\mathrm{r}} / \mathrm{B}\right) \approx 10^{-3}$. When multiple TAE modes are present, the orbit stochasticity threshold can be substantially reduced to $\left(\delta \mathrm{B}_{\mathrm{r}} / \mathrm{B}\right) \approx 10^{-4}$. The stochastic diffusion loss rate has been previously shown numerically to scale as $\left(\delta \mathrm{B}_{\mathrm{r}} / \mathrm{B}\right)^{2}$, and the loss rate can be drastically increased in case of multiple modes.

In experiments, the loss rate scaling with the TAE mode amplitude will be a mixture of these three scalings and will strongly depend on the plasma equilibrium, the TAE mode structure, and the duration of TAE mode activity. It should be pointed out that within an initial short period of time, the loss will always be linear with the wave amplitude even if the stochastic threshold is exceeded. In smaller machines like TFTR and DIII-D where the prompt loss boundary can be easily reached by energetic particles, it is found that the loss is dominated by the transient loss in the first 1000 transit time which is about 300 wave periods. As shown in Fig. 5(a) for TFTR and Fig. 5(b) for DIII-D, the total energetic particle loss scales linearly with the wave amplitude. Even for larger TAE mode amplitude runs where the diffusive loss is also observed, the transient loss mechanism still accounts for the major portion of the particle loss in the initial 1000 transit times. For bursting TAE activity, it is more likely that the total energetic particle loss scales linearly with the wave amplitude, as observed experimentally. However, it is expected that the diffusive loss mechanism can be more important for saturated large amplitude TAE modes with amplitudes exceeding the stochastic threshold for a longer duration.

\subsection{Quasi-Linear and Nonlinear Transport due to TAE Modes}


Energetic/alpha particle transport due to TAE modes and TAE mode saturation have also been simulated by a quasi-linear (ORBIT) [10] code and a nonlinear kinetic-MHD (MH3D-K) code [11]. The quasi-linear kinetic-MHD simulations include particle orbit width, nonlinear particle dynamics and the effects of the TAE modes on the particles. The core plasma is described by ideal MHD and the hot plasma by the gyro-kinetic equation. Additional damping such as the ion and electron Landau damping, collisional damping and continuum damping are taken as parameters supplied by other analyses. Assuming that the TAE mode structure does not change, the mode amplitude and phase are computed from the complex eigenfrequency of the quasi-linear dispersion relation and the time-dependent particle distribution function. Typically ten thousand particles are used in the simulations. The initial spatial distribution is Gaussian and we use a slowing-down energy distribution with uniform pitch angle. The dispersion relation is solved every 10 particle transit times $(2 \pi R / v)$ which is much smaller than the bounce time in our case. Simulations have been performed with parameters typical for TFTR and ITER.

Without a strong and steady energetic/alpha particle source, the profile modification is found to be the most efficient means of achieving TAE mode saturation. Resonant particles trapped in the wave produce flattening of the local pressure gradient. Also, the particle energy gradient becomes steeper since high energy particles lose energy whereas low energy particles do not interact with the mode, so the mode further loses drive due to increased velocity space Landau damping and eventually saturates. As in previous studies of TAE mode induced particle loss [9,15], the dominant loss process is that of barely counter-passing particles losing energy to the wave, transferring into fat banana orbits, and then hitting the outside wall in the co-moving direction. The losses are very effective for particles with large banana width. For ITER the particle loss is very small due to small banana width, and the alpha particles remain in the device and contribute to mode damping so that TAE modes saturate at very small amplitude as shown in Fig. 6, which shows the $n=1$ TAE mode amplitude versus time for ITER with $1 \%$ alpha particle beta and three alpha pressure gradient scale lengths. The time scale for the profile modification is orders of magnitude shorter than the time scale for alpha replenishment, so the additional new alpha particles would not modify this result. For TFTR the TAE mode can grow until extensive alpha particle loss is produced because the banana width is large compared with the minor radius. When there is a strong energetic/alpha source such as in NBI, TAE bursts in time can occur in TFTR with large loss of energetic particles during each burst.

Nonlinear saturation of TAE modes has been studied by the MH3D-K code [11] which includes both the nonlinear wave-particle interaction and nonlinear MHD mode-coupling physics. 
The MH3D-K code typically requires 200 thousand particles to overcome the statistical noise. In the simulations the following parameters and profiles are used: $R / a=6, q(r)=1.2+0.9(r / a)^{2}, n_{e}(r)=$ $n_{e}(0)\left[1-0.8(r / a)^{2}\right]$, the central core plasma beta $\beta_{c}(0)=0.2 \%$, the central hot particle beta $\beta_{h}(0)$ is on the order of percents, the hot particle velocity distribution is a Maxwellian in parallel direction with the thermal velocity equal to the Alfvén speed at the center of plasma, and the perpendicular velocity is negligible. The TAE modes saturate due to nonlinear particle trapping in the wave which leads to local density profile flattening in a time scale of $1 / \omega_{b}$, where $\omega_{b}$ is the bounce frequency of particles trapped in the wave. At saturation $\omega_{b} \approx \gamma_{h}$, where $\gamma_{h}$ is the linear growth rate induced by the hot particles. Since nonlinear wave-particle trapping implies that $\omega_{b}$ is proportional to $\left(\delta \mathrm{B}_{\mathrm{r}} / \mathrm{B}\right)^{1 / 2}$, the saturation amplitude $\left(\delta \mathrm{B}_{\mathrm{r}} / \mathrm{B}\right)$ scales as $\gamma_{\mathrm{h}}{ }^{2}$. This result is clearly demonstrated by the nonlinear simulations of MH3D-K code in Fig. 7 which shows the dependence of the saturated amplitude $\left(\delta \mathrm{B}_{\mathrm{r}} / \mathrm{B}\right)$ on the growth rate $\left(\gamma_{\mathrm{h}} / \omega\right)$. For this simulation it can be estimated that $\left(\omega_{\mathrm{b}} / \omega\right) \approx 3\left(\delta \mathrm{B}_{\mathrm{r}} / \mathrm{B}\right)^{1 / 2}$, and $\omega_{\mathrm{b}} \approx 1.2 \gamma_{\mathrm{h}}$.

Nonlinear saturation mechanism of high-n TAE modes, mediated via Compton scattering off the bulk ions, has been investigated [23]. The nonlinear $\left(\vec{J}_{\perp} \times \vec{B}_{\perp}\right)$ ponderomotive force produced by TAE's interaction drives sound wave like density fluctuation with low phase velocity which can resonantly interact with the bulk ion parallel motion. Consequently, energy from an unstable TAE mode can be transferred to a weakly stable TAE mode of the same toroidal mode number but with lower frequency near the lower shear Alfvén continuum, leading to nonlinear saturation. Energy transfer is most efficient if the difference between the TAE frequencies is on the order of $\beta_{i^{1 / 2}}\left(v_{A} / 2 q R\right)$. The nonlinear saturation level of the high- $n$ TAE mode is given by $\left(\delta \mathrm{B}_{\mathrm{r}} / \mathrm{B}\right)^{2} \approx\left(1+\mathrm{T}_{\mathrm{e}} / \mathrm{T}_{\mathrm{i}}\right)^{2}\left(\gamma_{\mathrm{L}} / \omega_{\mathrm{A}}\right)(\mathrm{r} / \mathrm{R})^{4} / 4 \pi$, where $\gamma_{\mathrm{L}}$ is the linear TAE growth rate.

\section{Convective "Bucket" Transport}

Particle dynamics in chirped or swept waves (time-dependent frequency waves) has received great interest recently [12,13]. Particles interacting with a chirped electromagnetic perturbation will form drift orbit islands with a single-node separatrix, or bucket, in phase space. The bucket will move in phase space at a rate proportional to that of the frequency change. If the frequency is varied slowly, particles trapped inside the bucket will convect with it, whereas circulating particles colliding with the bucket will get a resonant kick. The size of the bucket and the resonant kick are both strong functions of the chirping parameter $\alpha_{c}=\ddot{\phi} / \omega_{b}{ }^{2}$, where $\phi(t)$ is

wave phase ( $\ddot{\phi}$ is the frequency change rate) and $\omega_{\mathrm{b}}$ is the bounce frequency of particles trapped in 
the wave. Bucket size will shrink with increasing $\alpha_{c}$ and vanishes when $\alpha_{c} \geq 1$. Therefore, the existence of the bucket requires that the wave phase acceleration rate should be less than the square of the bounce frequency in order for particles to be trapped inside a wave. When the bucket vanishes, particles will still get a kick when colliding with the moving resonant surfaces. When two buckets collide with each other, some trapped particles will leak out of the bucket, and after the buckets depart from each other, each will carry some particles along. If the frequency chirping parameter $\alpha_{c}$ is increasing in time, the bucket size will be shrinking and some particles will be squeezed out along the way.

A magnetic perturbation in an axisymmetric toroidal system with $\delta B_{r}=\delta B_{m, n}(r) \sin [m \theta-$ $\mathrm{n} \zeta-\omega(\mathrm{t}) \mathrm{t}]$, where $\mathrm{m}$ is the poloidal mode number and $\mathrm{n}$ is the toroidal mode number, can induce a particle drift orbit island (or 'bucket') at resonant surface determined by the resonance condition $m \omega_{\theta}-n \omega_{\zeta}=\omega(t)$, where $\omega_{\theta}=\dot{\theta}$, and $\omega_{\zeta}=\dot{\zeta}$. For passing particles one has $\omega_{\zeta} \approx v \| / R$ and $\omega_{\theta} \approx$ $\mathrm{v}_{\|} / \mathrm{qR}$, and $\mathrm{v}_{\|}$is the transit-averaged parallel velocity. Thus, at resonance $\mathrm{q}(\mathrm{r}(\omega))=(\mathrm{m} / \mathrm{n}) /[1+$ $\left.\left(\omega / n \omega_{\zeta}\right)\right]$. When $\omega(t)$ is varied slowly, a particle in the bucket will move adiabatically with the bucket at a radial velocity $\dot{\mathrm{r}}=\dot{\mathrm{q}} / \mathrm{q}^{\prime}$ with $\dot{\mathrm{q}}=-\mathrm{q} \dot{\omega} / \mathrm{m} \omega_{\theta}$.

In terms of a more rigorous Hamiltonian formulation, the radial motion of the bucket and the nonlinear particle bounce frequency in the chirped wave have been calculated by assuming large aspect ratio and thin orbit width [12]. For well passing particles we have

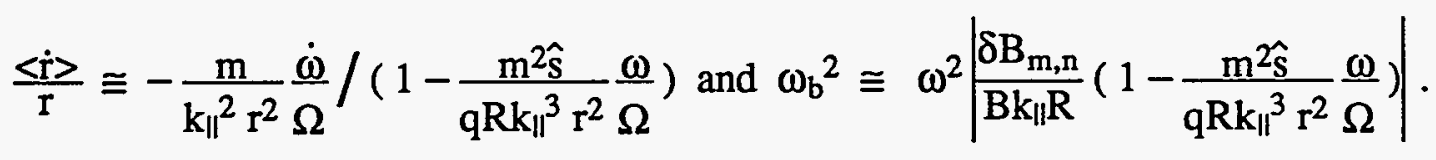

where $\langle r\rangle$ is the bounce/transit averaged radial particle position, $\hat{s}=r q / q$ is the magnetic shear, $k_{\|}$ is the parallel wave vector, $\Omega$ is the gyro-frequency. For deeply trapped particles we have

$$
\begin{aligned}
\frac{\langle\dot{r}\rangle}{r} & \equiv-\dot{\omega} /\left[(1-\hat{s}) \omega+(2-3 \hat{s}) m \omega_{\theta}-\frac{m \omega_{\theta}^{2}}{8 n \omega_{\zeta}}\right] \\
\text { and } \quad \omega_{b}^{2} & \equiv 2 n \omega_{\zeta} \mid \frac{\delta B_{m, n}}{B k_{\|} r}\left[(1-\hat{s}) \omega+(2-3 \hat{s}) m \omega_{\theta}-\frac{m \omega_{\theta}^{2}}{8 n \omega_{\zeta}}\right] .
\end{aligned}
$$

Note that the bucket existence condition is $\alpha_{c}=\dot{\omega} / \omega_{b}{ }^{2}<1$. For barely trapped particles, their orbits can easily become stochastic and can lead to leaking of the bucket because there are many closely packed resonant surfaces. By assuming a positive poloidal mode number, it is typical that particles 
inside the bucket will move radially outward while losing energy if the frequency is swept down. The resulting radial particle flux due to the chirped wave will be proportional to the product of the frequency chirping rate and the bucket size.

Because of the energy-selective characteristics of the bucket transport, frequency chirping perturbations may be intentionally applied as a mean to redistribute radially particles of a certain energy range. There are many potential applications of this mechanism. For instance, the bucket transport mechanism opens the possibility of helium ash or impurity removal, energetic fuel ion injection for burn control, profile control of locally produced particles away from particular radial resonance location to avoid instabilities, and maintaining good confinement of both the fast alphas and the thermal bulk plasma. The He ash-removal application of the bucket transport mechanism has been simulated for externally excited perturbations with amplitude below the stochastic diffusion threshold $[12,13]$. A single bucket sweep will not capture all the particles in the target distribution. If the frequency sweeping time $\tau_{s w}$ is small compared with the alpha particle slowingdown time $\tau_{\text {sl }}$, many sweeps can be used to access particles of different energy, pitch angle and radial location. Consider TFTR parameters with $\mathrm{a}=96 \mathrm{~cm}, \mathrm{R}=2.62 \mathrm{~m}, \mathrm{~B}=5 \mathrm{~T}, \mathrm{q}(0)=1, \mathrm{q}(\mathrm{a})=$ 4 , and $\tau_{\mathrm{sl}}=200 \mathrm{msec}$ for the alpha birth energy $\mathrm{E}_{\mathrm{o}}=3.5 \mathrm{MeV}$. The initial particle distribution consists of 9 monoenergetic ensembles of co-going particles at $E / E_{0}=\left\{10^{-2}, 10^{-1.75}, \ldots, 1\right\}$, and with radii in the range of $r / R=0.01$ to 0.1 , and pitch angle in the range $\lambda=v_{\|} / v=0.6$ to 0.9 . The magnetic perturbation has $n=1, m=2$, and $\delta B_{\mathrm{r}} / \mathrm{B}=4 \times 10^{-4}$, which is well below the stochastic diffusion threshold. The frequency is swept from $\omega_{1}=4 \times 10^{-3} \Omega$ to $\omega_{2}=-\omega_{1} / 2$ in a sweeping time of $\tau_{\mathrm{SW}}=200 \tau_{\zeta}$, where $\tau_{\zeta}$ is the particle toroidal transit time, and $\Omega$ is the alpha gyrofrequency ( $\tau \zeta \approx 4 \mu \mathrm{sec}, \Omega \approx 2.38 \times 10^{8} \mathrm{~s}^{-1}$ ). Figure 8 plots the particle ensemble-averaged radius $\langle r\rangle$ versus time, in unit of the number of sweeps. Clearly, particles with $\mathrm{E} / \mathrm{E}_{\mathrm{o}} \approx 0.1$ are selectively transported to large radius.

\section{Summary}

The NOVA-K code has previously been employed to study TAE stability in NBI and ICRF experiments in TFTR D-D discharges. Reasonably good agreement between theory and experiment has been achieved. Further improvements on the physics content of the NOVA-K code over the past two years have enable us to analyze the TAE instabilities in TFTR D-T and DIII-D experiments with better physics understandings of TAE instability drive and damping mechanisms. We have also studied the TAE stability with ITER EDA parameters and found that TAE modes may be unstable in normal ITER operations. The energetic particle transport mechanism due to TAE 
modes has been investigated and the transport can-be large for. TFTR and DIII-D for $\delta \mathrm{B}_{\mathrm{r}} / \mathrm{B}>10^{-4}$. The nonlinear saturation of TAE modes is due to nonlinear wave particle trapping and energetic particle profile modification in radial and energy space. Finally, a convective bucket transport mechanism by MHD waves with time dependent frequency is presented. Based on the energyselective characteristics of the bucket transport mechanism, undesirable particles such as helium ash can be removed from the plasma core.

\section{ACKNOWLEDGMENTS}

This work is supported by U.S. Department of Energy Contract No. DE-AC02-76-CHO3073 at Pinceton Plasma Physics Laboratory, Grant No. DE-FG02-91-ER-54109 at MIT Plasma Fusion Center, Grant No. DE-FG03-92ER-54150 at General Atomics, and Grant No. DE-FG0394ER-54271 at University of California at Irvine.

\section{REFERENCES}

1. Cheng, C. Z., Chance, M. S., Phys. Fluids 29, 3695 (1986).

2. Cheng, C. Z., Chen, L., Chance, M. S., Ann. Phys. (NY) 161, 21 (1985).

3. Wong, K. L., et al., Phys. Rev. Lett. 66, 1874 (1991).

4. Heidbrink, W. W., Strait, E. J., Doyle, E., Snide, R., Nucl. Fusion 31, 1635 (1991).

5. Wu, Y., Cheng, C. Z., White, R. B., PPPL-2979 (1994).

6. Cheng, C. Z., Fusion Technology 18, 443 (1990).

7. Cheng, C. Z., Phys. Reports, 2111, 1 (1992).

8. Fu, G. Y., Cheng, C. Z., Wong, K. L., Phys. Fluids B 5, 4040 (1993).

9. Sigmar, D. J., Hsu, C. T., White, R. B., Cheng, C. Z., Phys. Fluids B4, 1506 (1992).

10. Wu, Y., White, R. B., Cheng, C. Z., PPPL-2980 (1994); Wu, Y., White, R. B., Phys. Plasmas 1, 2733 (1994)

11. Fu, G. Y., Cheng, C. Z., Park, W., Budny, R., International Sherwood Theory Meeting, 1994; Park, W., et al., Phys. Fluids B4, 2033 (1992).

12. Hsu, C. T., Cheng, C. Z., Helander, P., Sigmar, D. J., White, R. B., Phys. Rev. Lett. 92, 2503 (1994).

13. Mynick, H. E., Pomphrey, N., PPPL-2970 (1994), to appear in Nucl. Fusion (1994).

14. Fu, G. Y., Cheng, C. Z., Phys. Fluids B 2, 985 (1990). 
15. Cheng, C. Z., et al., 14th International Conference on Plạsma Physics and Controlled Nuclear Fusion Research, paper IAEA-CN-56/D-2-1(C), Wurzburg, Germany, 1992.

16. Cheng, C. Z., Fu, G. Y., Van Dam, J. W., in Proceedings of Workshop on Theory of Fusion Plasmas, Chexbres, Switzerland, 1988 (ed. J. Vaclavik, F. Troyon, and E. Sindoni, Societa Italiana di Fisica, Bologna, 1989), p. 259.

17. Fu, G. Y., Van Dam, J. W., Phys. Fluids B 1, 1949 (1989).

18. Cheng, C. Z., Phys. Fluids B, 3 (1991) 2463.

19. Harley, T. R., Cheng, C. Z., Jardin, S. C., J. Compt. Phys. 103, 43 (1992).

20. Hawryluk, R. L., et al., Phys. Rev. Lett., 72, 3530 (1994).

21. Strachan, J. D., et al., Phys. Rev. Lett., 72, 3526 (1994).

22. Strait, E. J., Heidbrink, W. W., Turnbull, A. D., Chu, M. S., Duong, H. H., Nucl. Fusion 33, 12 (1993).

23. Hahm, T. S., Chen, L., PPPL-3022 (1994). 


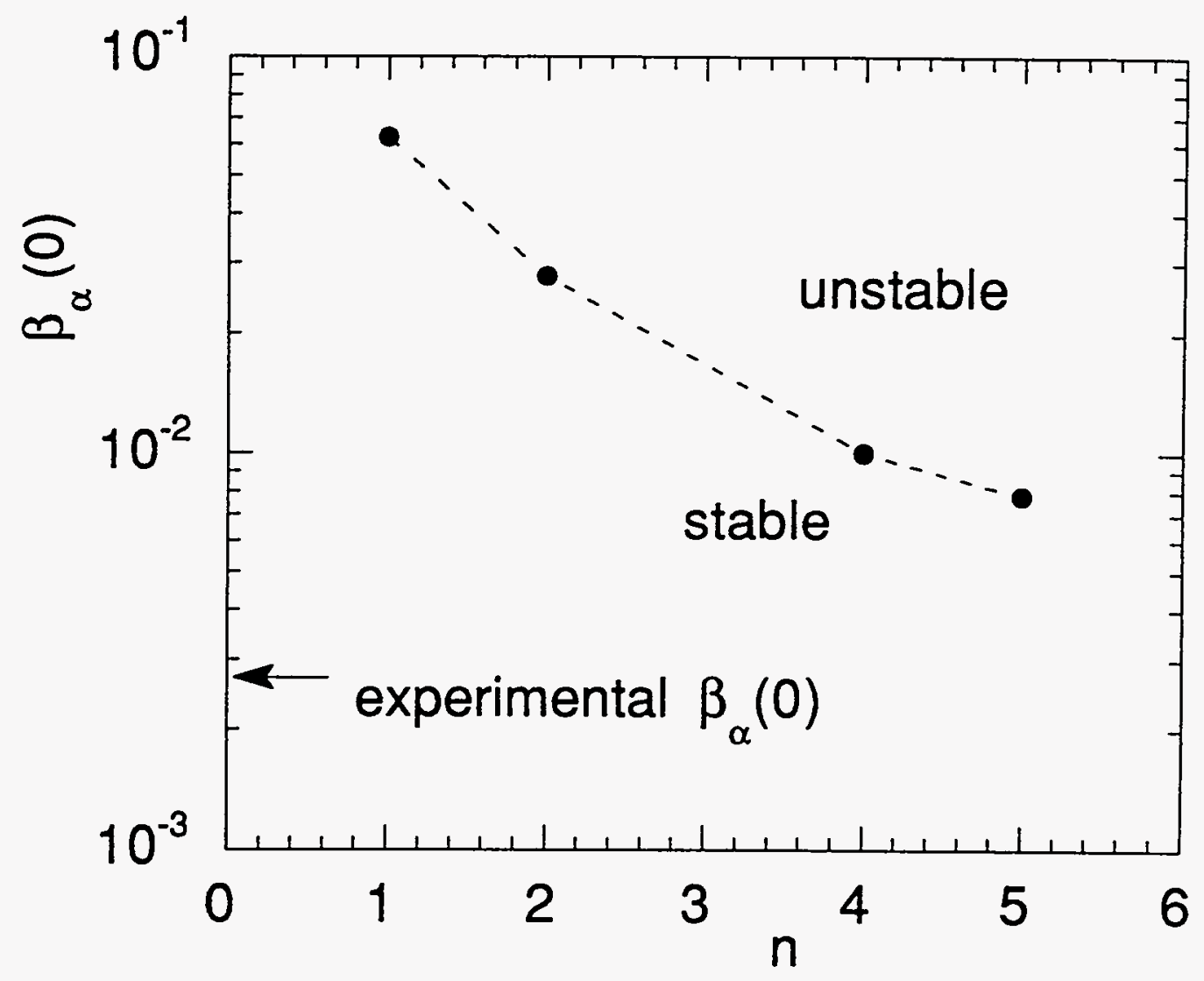

Fig. 1 The critical $\beta_{\alpha}(0)$ for TAE instability versus the toroidal mode number for a TFTR D-T shot (\#73268) at $3.4 \mathrm{sec}$. The experimental $\beta_{\alpha}(0)$ value is about $1 / 3$ of the $\beta_{\alpha}(0)$ threshold for the $n=5$ mode. 


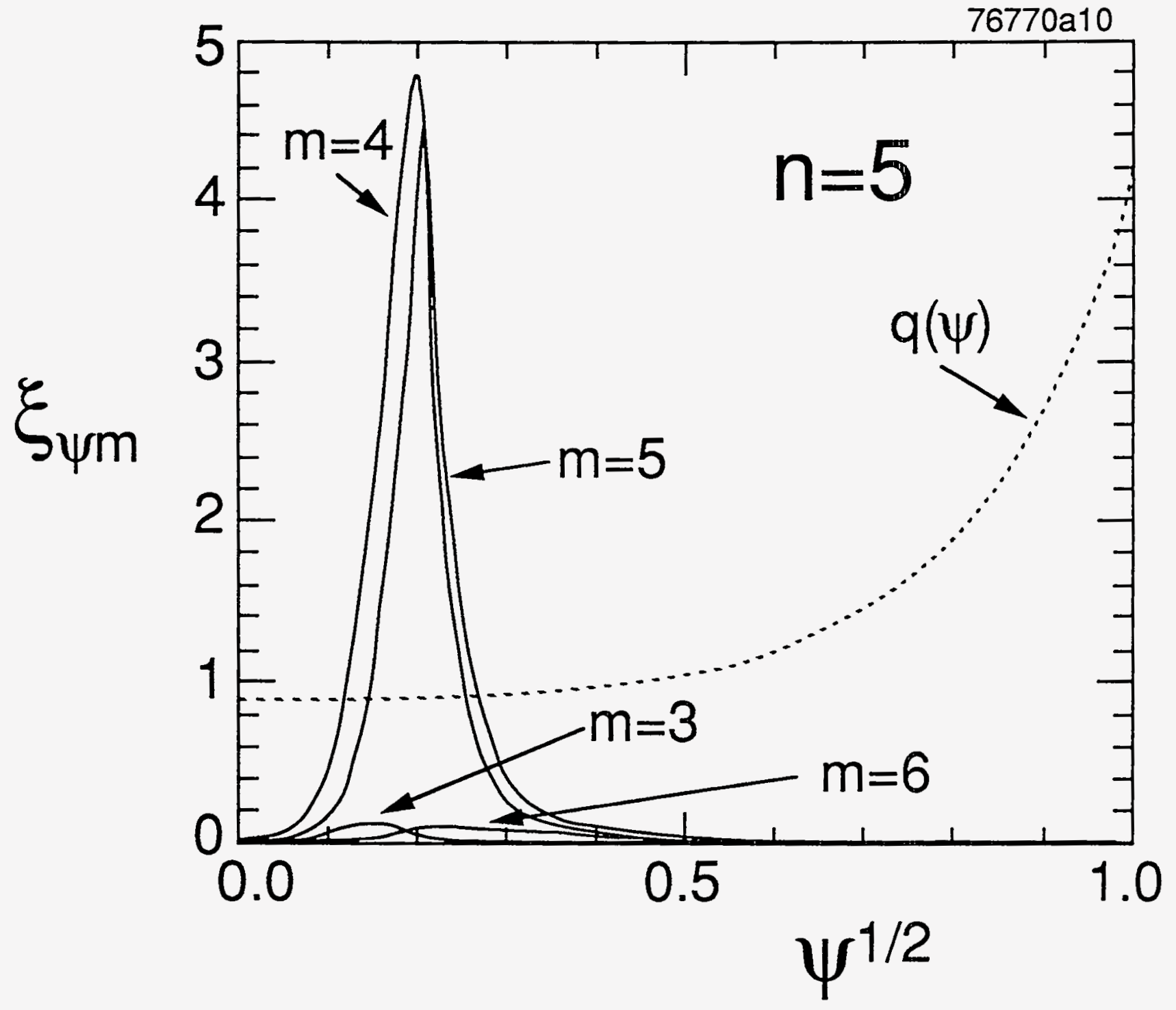

Fig. 2 The poloidal harmonics of eigenfunction $\xi_{\psi}$ of the $n=5$ fixed boundary TAE mode versus square root of normalized poloidal flux for a TFTR D-T shot (\#76770) at $4.31 \mathrm{sec}$. The frequency of the $\mathrm{n}=5 \mathrm{TAE}$ mode is given by $\left(\omega / \omega_{\mathrm{A}}\right)^{2}=4.04$, where $\omega_{A}=V_{A}(0) / q(a) R$. 

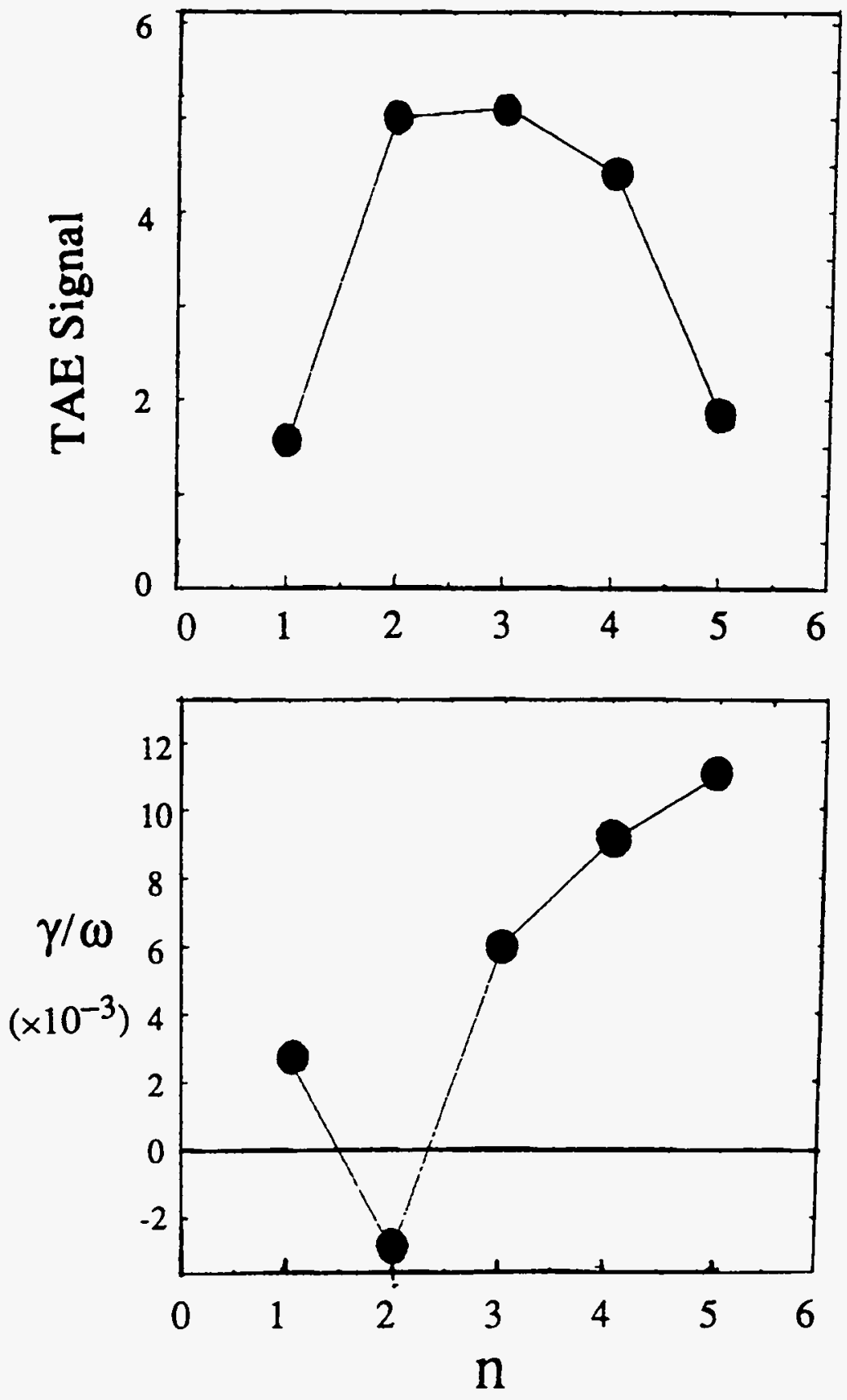

Fig. 3 (a) TAE mode signal versus toroidal mode number $n$ for a DIII-D shot (\#71524). (b) TAE growth rate versus $n$ computed from the NOVA-K code. 


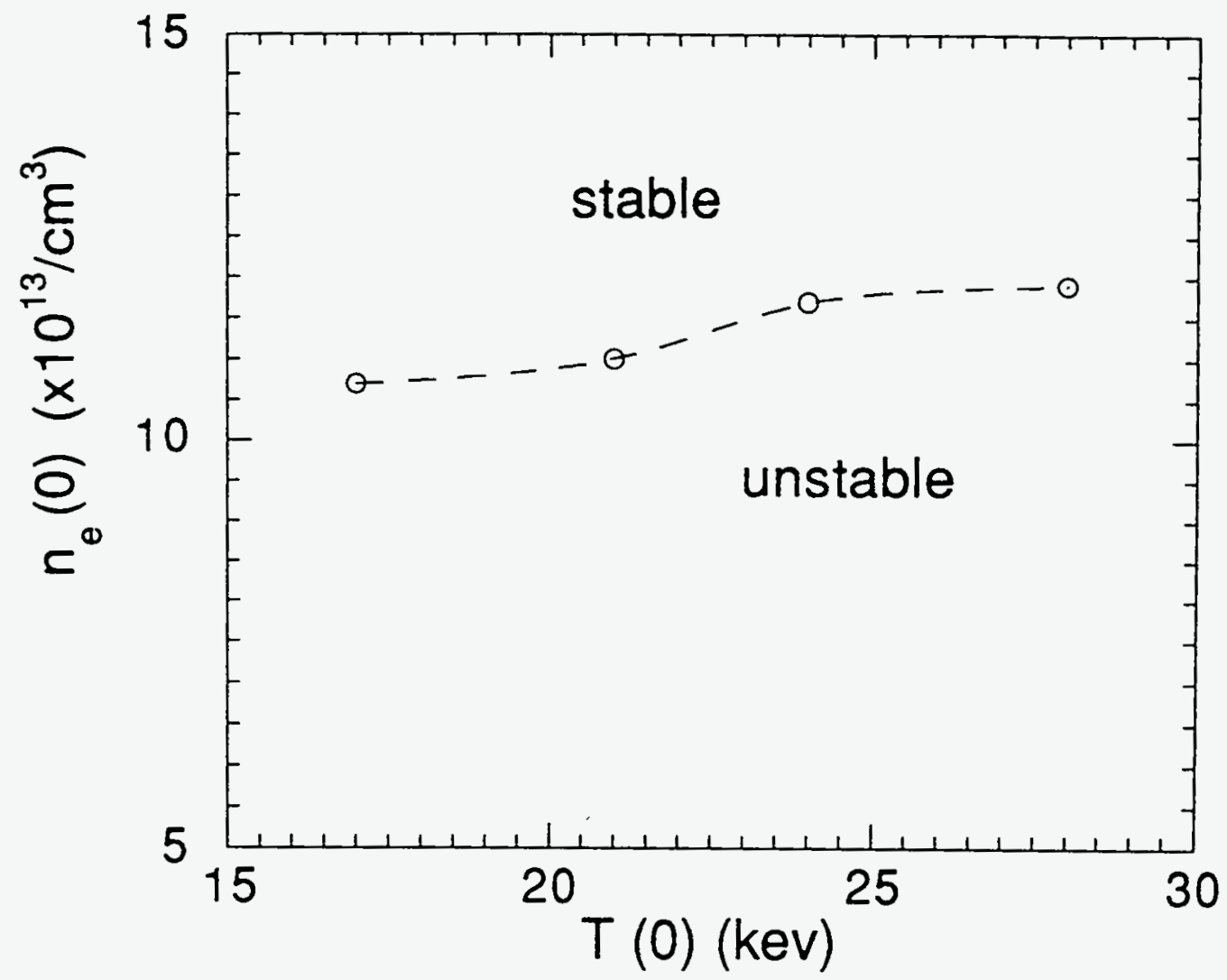

Fig. 4 The stability boundary in the $n_{e}(0)-T(0)$ POPCON diagram for a $n=15$ TAE mode in ITER EDA. 

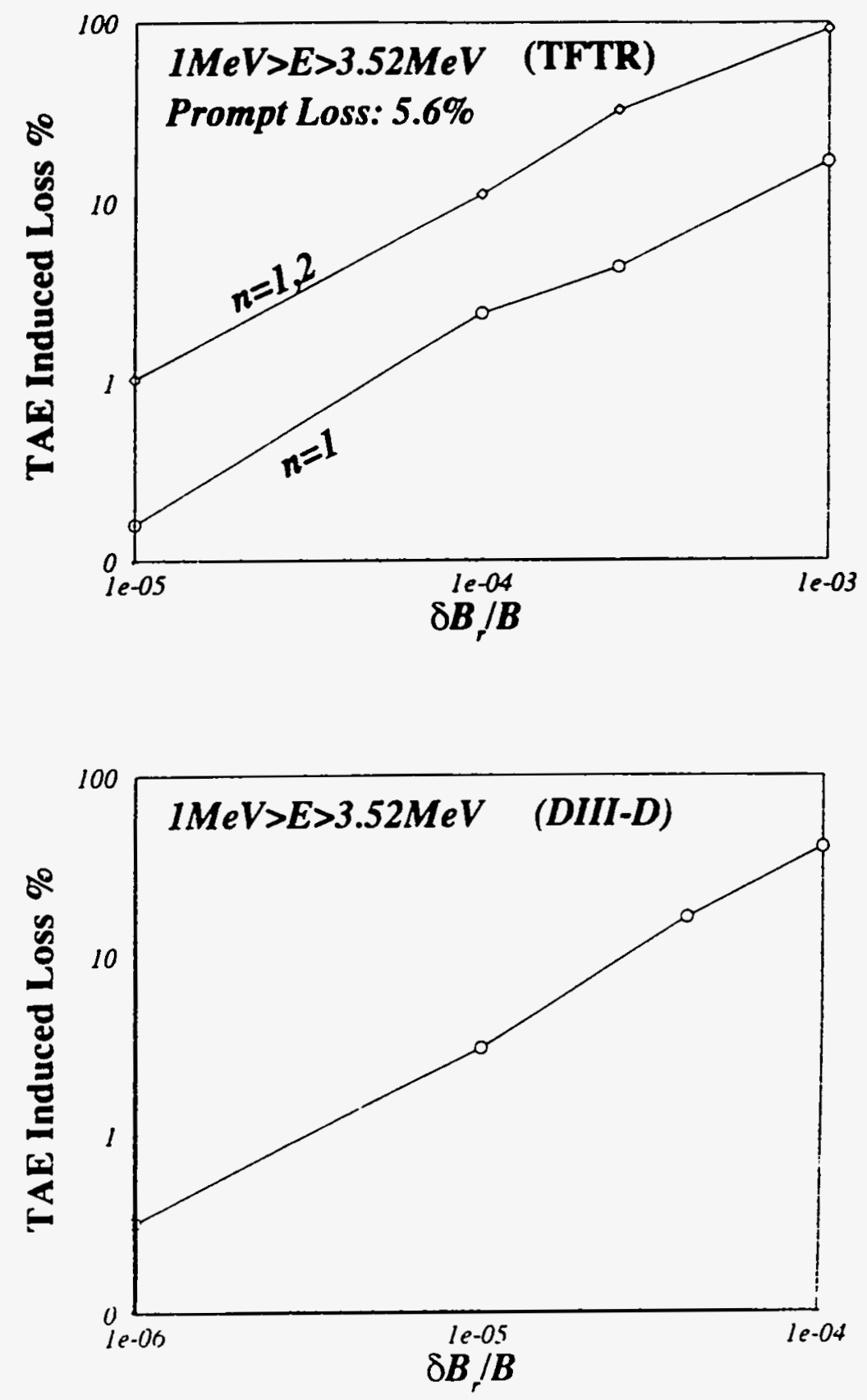

Fig. 5 Energetic particle loss scaling with the TAE amplitude for (a) TFTR and (b) DIII-D computed from ORBIT code. 


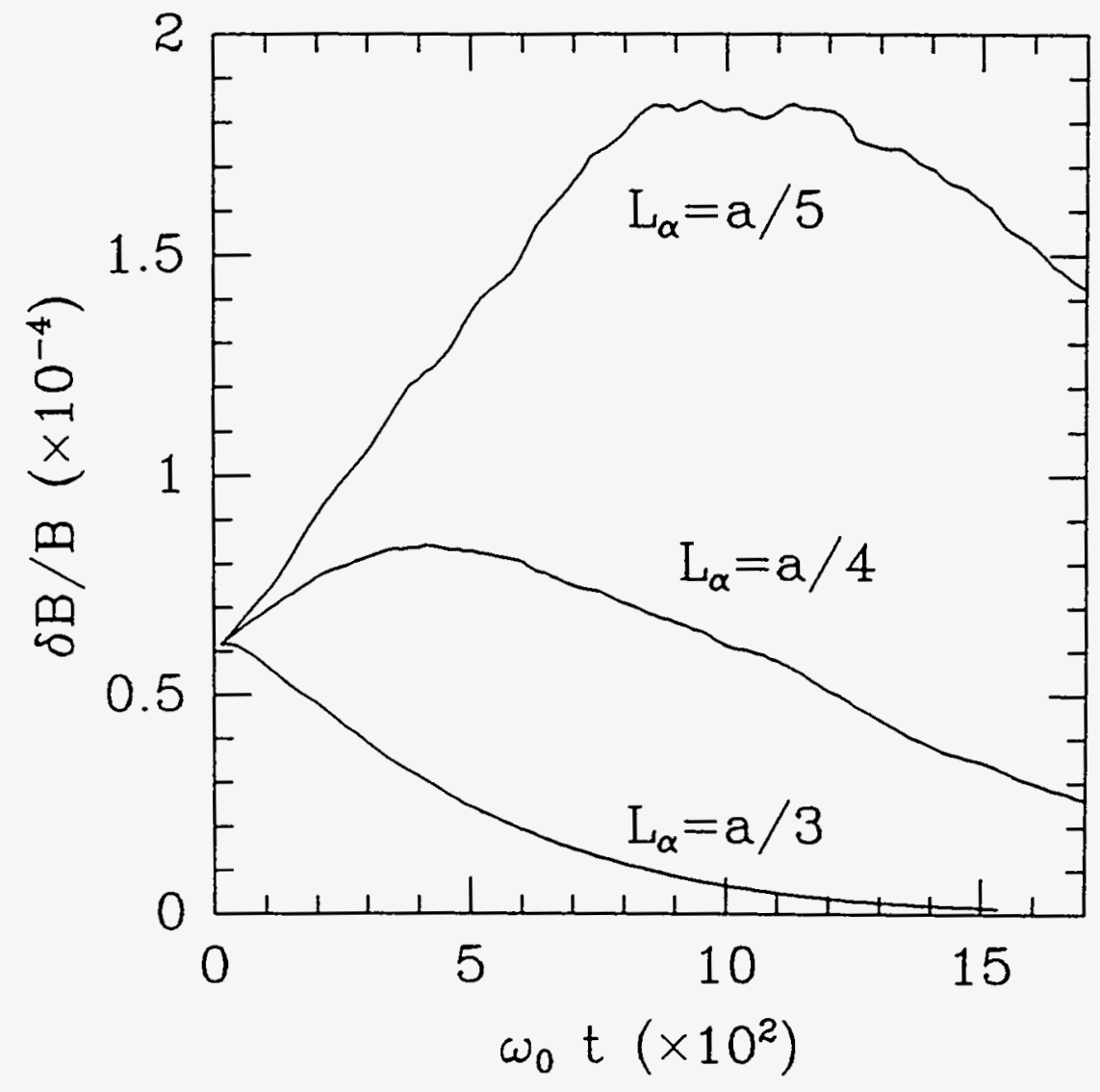

Fig. 6 Quasi-linear simulation of TAE amplitude $\left(\delta \mathrm{B}_{\mathrm{r}} / \mathrm{B}\right)$ versus time for ITER with a $1 \%$ alpha particle beta and three different alpha pressure gradient scale lengths. 


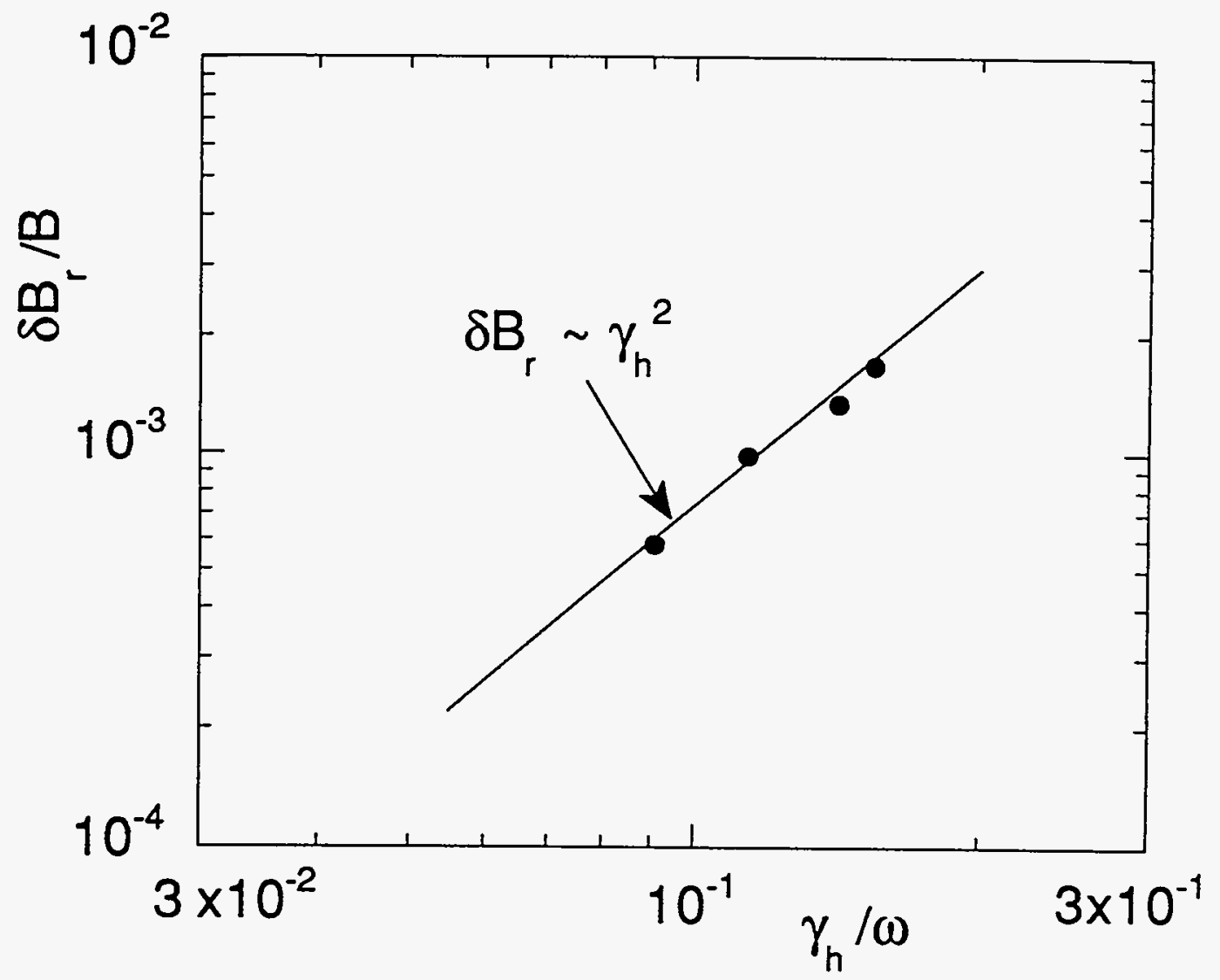

Fig. 7 The MH3D-K code simulation of the TAE saturation amplitude $\left(\delta \mathrm{B}_{\mathrm{r}} / \mathrm{B}\right)$ versus the TAE linear growth rate $\left(y_{/} / \omega\right)$. 


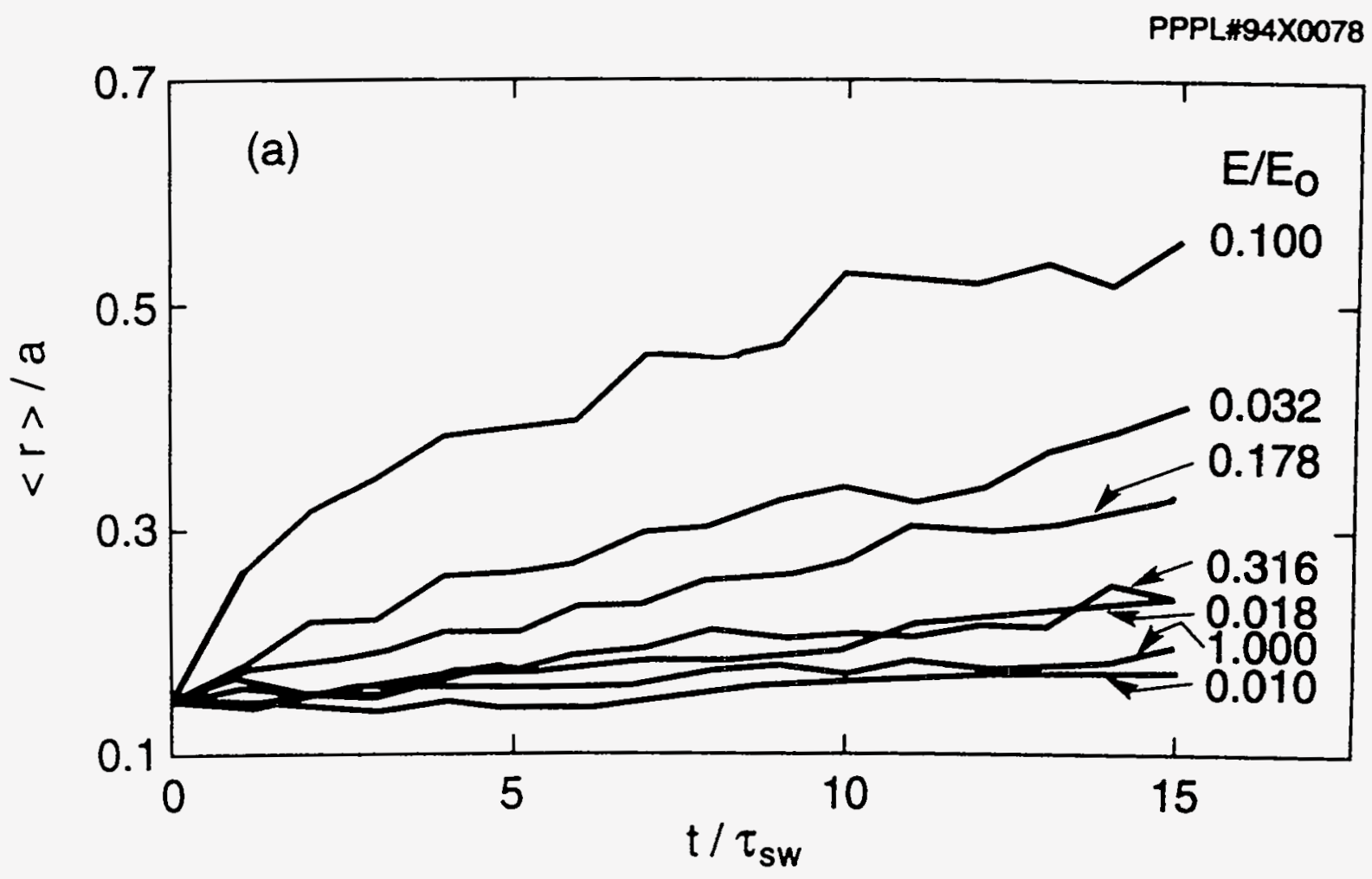

Fig. 8 Plot of ensemble-averaged radius of particles versus time, in units of the number of sweeps applied, for an ensemble of co-going particles initially located in the radial range $r / R=0.01$ to 0.1 with 9 energies $E / E_{0}=\left\{10^{-2}, 10^{-1.75}, \ldots, 1\right\}$. 
Dr. F. Paoloni, Univ. of Wollongong, AUSTRALIA

Prof. R.C. Cross, Univ. of Sydney, AUSTRALIA

Plasma Research Lab., Australian Nat. Univ., AUSTRALIA

Prof. I.R. Jones, Flinders Univ, AUSTRALIA

Prof. F. Cap, Inst. for Theoretical Physics, AUSTRIA

Prof. M. Heindler, Institut für Theoretische Physik, AUSTRIA

Prof. M. Goossens, Astronomisch Instituut, BELGIUM

Ecole Royale Militaire, Lab. de Phy. Plasmas, BELGIUM

Commission-European, DG. XII-Fusion Prog., BELGIUM

Prof. R. Bouciqué, Rijksuniversiteit Gent, BELGIUM

Dr. P.H. Sakanaka, Instituto Fisica, BRAZIL

Prof. Dr. I.C. Nascimento, Instituto Fisica, Sao Paulo, BRAZIL Instituto Nacional De Pesquisas Espaciais-INPE, BRAZIL

Documents Office, Atomic Energy of Canada Ltd., CANADA

Ms. M. Morin, CCFWTokamak de Varennes, CANADA

Dr. M.P. Bachynski, MPB Technologies, Inc., CANADA

Dr. H.M. Skarsgard, Univ. of Saskatchewan, CANADA

Prof. J. Teichmann, Univ. of Montreal, CANADA

Prof. S.R. Sreenivasan, Univ. of Calgary, CANADA

Prof. T.W. Johnston, INRS-Energie, CANADA

Dr. R. Bolton, Centre canadien de fusion magnétique, CANADA

Dr. C.R. James, Univ. of Alberta, CANADA

Dr. P. Lukác, Komenského Universzita, CZECHO-SLOVAKIA

The Librarian, Culham Laboratory, ENGLAND

Library, R61, Rutherford Appleton Laboratory, ENGLAND

Mrs. S.A. Hutchinson, JET Library, ENGLAND

Dr. S.C. Sharma, Univ. of South Pacific, FIJI ISLANDS

P. Mähönen, Univ. of Helsinki, FINLAND

Prof. M.N. Bussac, Ecole Polytechnique,, FRANCE

C. Mouttet, Lab. de Physique des Milieux lonisés, FRANCE

J. Radet, CEN/CADARACHE - Bat 506, FRANCE

Prof. E. Economou, Univ. of Crete, GREECE

Ms. C. Rinni, Univ. of loannina, GREECE

Preprint Library, Hungarian Academy of Sci., HUNGARY

Dr. B. DasGupta, Saha Inst. of Nuclear Physics, INDIA

Dr. P. Kaw, Inst. for Plasma Research, INDIA

Dr. P. Rosenau, Israel Inst. of Technology, ISRAEL

Librarian, International Center for Theo Physics, ITALY

Miss C. De Palo, Associazione EURATOM-ENEA, ITALY

Dr. G. Grosso, Istituto di Fisica del Plasma, ITALY

Prof. G. Rostangni, Istituto Gas Ionizzati Del Cnr, ITALY
Dr. H. Yamato. Toshiba Res \& Devel Center, JAPAN

Prof. I. Kawakami, Hiroshima Univ., JAPAN

Prof. K. Nishikawa, Hiroshima Univ., JAPAN

Librarian, Naka Fusion Research Establishment, JAERI, JAPAN

Director, Japan Atomic Energy Research inst., JAPAN

Prof. S. Itoh, Kyushu Univ., JAPAN

Research Info. Ctr., National Instit. for Fusion Science, JAPAN

Prof. S. Tanaka, Kyoto Univ., JAPAN

Library, Kyoto Univ., JAPAN

Prof. N. Inoue, Univ. of Tokyo, JAPAN

Secretary, Plasma Section, Electrotechnical Lab., JAPAN

Dr. O. Mitarai, Kumamoto Inst. of Technology, JAPAN

Dr. G.S. Lee, Korea Basic Sci. Ctr., KOREA

J. Hyeon-Sook, Korea Atomic Energy Research Inst., KOREA

D.I. Choi, The Korea Adv. Inst. of Sci. \& Tech., KOREA

Prof. B.S. Liley, Univ. of Waikato, NEW ZEALAND

Inst of Physics, Chinese Acad Sci PEOPLE'S REP. OF CHINA

Library, Inst. of Plasma Physics, PEOPLE'S REP. OF CHINA

Tsinghua Univ. Library, PEOPLE'S REPUBLIC OF CHINA

Z. Li, S.W. Inst Physies, PEOPLE'S REPUBLIC OF CHINA

Prof. J.A.C. Cabral, Instituto Superior Tecnico, PORTUGAL

Prof. M.A. Hellberg, Univ. of Natal, S. AFRICA

Prof. D.E. Kim, Pohang Inst. of Sci. \& Tech., SO. KOREA

Prof. C.I.E.M.A.T, Fusion Division Library. SPAIN

Dr. L. Stenflo, Univ. of UMEA, SWEDEN

Library, Royal Inst. of Technology, SWEDEN

Prof. H. Wilhelmson, Chalmers Univ. of Tech., SWEDEN

Centre Phys. Des Plasmas, Ecole Polytech. SWITZERLAND

Bibliotheek, Inst. Voor Plasma-Fysica, THE NETHERLANDS

Asst. Prof. Dr. S. Cakir, Middle East Tech. Univ., TURKEY

Dr. V.A. Glukhikh,Sci. Res. Inst. Electrophys.I Apparatus, USSR

Dr. D.D. Ryutov, Siberian Branch of Academy of Sci., USSR

Dr. G.A. Eliseev, I.V. Kurchatov Inst., USSR

Librarian, The Ukr.SSR Academy of Sciences, USSR

Dr. L.M. Kovrizhnykh, Inst. of General Physics, USSR

Kemforschungsanlage GmbH, Zentralbibliothek, W. GERMANY

Bibliothek, Inst. Für Plasmaforschung, W. GERMANY

Prof. K. Schindler, Ruhr-Universitát Bochum, W. GERMANY

Dr. F. Wagner, (ASDEX), Max-Planck-Institut, W. GERMANY

Librarian, Max-Planck-Institut, W. GERMANY 